\title{
Assessment of physical function, quality of life, and medication adherence in elderly patients with rheumatic diseases
}

\author{
Tuba Erdem Sultanoğlu* (D, Safinaz Ataoğlu(D, Burcu Avşar@i and Ömer Faruk Merkür@
}

\begin{abstract}
Background: The proportion of older people in the total population has increased in Turkey as well as worldwide. As life expectancy rises, the increasing prevalence of rheumatic diseases poses major problems in the elderly. Comorbid diseases and the aging-induced changes in the endogenous immune response and the pharmacokinetic properties of therapeutic agents may complicate the decision to use a particular drug and result in a different clinical picture and treatment response. We, therefore, aimed to investigate the characteristics of chronic inflammatory diseases, their impact on physical function and quality of life, the prevalence of comorbid diseases that may complicate treatment planning, and treatment adherence in patients aged 65 years or older.

Results: One hundred seventy-four patients were included and divided into two age groups: 18-64 years (group 1, $n=85$ ) and 65 years or older (group $2, n=89$ ). The mean age of all recruited patients was $57.55 \pm 16.98$ years. Of 174,99 (56.9\%) were female and 75 (43.1\%) were male. The mean duration of rheumatic disease was $7 \pm 4.8$ years and age at onset was $51.46 \pm 14.78$ years. Gender distribution differed significantly by age group $(P=0.024)$. The percentage of females in group 1 was $48.2 \%$ and $65.2 \%$ in group 2 . The occupational status also differed significantly by age group ( $P<0.001)$. 48.2\% of group 1 were employed and $57.3 \%$ of group 2 were housewives. Marital status varied significantly by age $(P<0.001)$. The percentage of married was $74.1 \%$ in group 1 and the percentage of separated/divorced/widowed in group 2 was $28.1 \%$. There was no difference between groups 1 and 2 in terms of place of residence $(P=0.459)$. The prevalence of comorbid diseases and the rate of use of medications for comorbid diseases (non-rheumatic treatments) were higher in elderly patients. The rate of use of disease-modifying anti-rheumatic drugs (DMARDs) was 30.3\% and biological agents $61.8 \%$ in the elderly group ( $\geq 65$ years) (group 2) $(P<0.001)$. There were positive correlations between, Health Assessment Questionnaire (HAQ), Bath Ankylosing Spondylitis Functional Index (BASFI) and Nottingham Health Profile (NHP) domains in both groups. There was also a significant negative correlation between Medication Adherence Rating Scale (MARS) and all dimensions.

Conclusions: Elderly and younger patients with rheumatic diseases have different demographic and clinical characteristics. Physical function and quality of life are more affected by rheumatic diseases and treatment adherence is poorer in the elderly. Our study found a positive correlation between physical function and quality of life in both age groups. The treatment adherence rating scale showed a negative correlation with physical function and quality of life scores, with individuals with poor treatment adherence having worse physical function and quality of life.
\end{abstract}

Keywords: Rheumatic diseases, Geriatrics, Physical function, Quality of life, Treatment adherence

\footnotetext{
* Correspondence: drtubaerdem@gmail.com

Department of Physical Medicine and Rehabilitation, Düzce University Faculty of Medicine, Düzce, Turkey
}

\section{Springer Open}

(c) The Author(s). 2021 Open Access This article is licensed under a Creative Commons Attribution 4.0 International License, which permits use, sharing, adaptation, distribution and reproduction in any medium or format, as long as you give appropriate credit to the original author(s) and the source, provide a link to the Creative Commons licence, and indicate if changes were made. The images or other third party material in this article are included in the article's Creative Commons licence, unless indicated otherwise in a credit line to the material. If material is not included in the article's Creative Commons licence and your intended use is not permitted by statutory regulation or exceeds the permitted use, you will need to obtain permission directly from the copyright holder. To view a copy of this licence, visit http://creativecommons.org/licenses/by/4.0/. 


\section{Background}

The proportion of older people in the total population is increasing both in Turkey and worldwide. Recognition of risks and improvement of care options in response to increasing life expectancy increases the number of people with at least one chronic disease [1]. According to data from Turkish Statistical Institute, the proportion of people aged 65 years or older defined as elderly was $8.7 \%$ in 2018 , but is projected to reach $10.2 \%$ in 2023 , $16.3 \%$ in $2040,22.6 \%$ in 2060 , and $25.6 \%$ in 2080 [2, 3]. Chronic inflammatory diseases affect $3 \%$ of the total population. Life expectancy continues to rise, increasing the incidence of rheumatic diseases in the elderly [4]. In the geriatric age group, rheumatic diseases may begin with non-specific constitutional symptoms (e.g., malaise, fever, weight loss), while these clinical symptoms may differ from those of young people. Comorbid diseases and the aging-induced changes in the endogenous immune response, as well as the pharmacokinetic properties of therapeutic agents, may complicate the decision to use a particular drug and result in a variable clinical picture and treatment response. Therefore, the use of immunosuppressants and corticosteroids in the elderly can be problematic because of comorbid diseases and an increased risk of adverse drug reactions. The chronic course of rheumatic diseases and their impact on physical function can lead to severe disability in the elderly. While the main goal in young patients is to treat the disease, in the elderly the goal is to improve or maintain function at a plateau. Maintaining physical function and improving quality of life are important aspects of treatment [4-6]. Treatment adherence is an important factor in symptom control and treatment success in chronic disease management. The World Health Organization (WHO) defines treatment adherence as patients' internalization of general or medical health recommendations, taking prescribed medications at appropriate doses and frequencies, following dietary and health recommendations, and maintaining lifestyle changes. According to 2003 data from WHO, long-term adherence to treatment for chronic diseases is about $50 \%$ and even lower in developing countries $[7,8]$.

The aim of our study was to investigate the characteristics of chronic inflammatory diseases, their impact on physical function and quality of life, the prevalence of comorbid diseases that might complicate treatment planning, and treatment adherence in patients aged 65 years or older; we also aimed to compare these data with those of patients aged 18-64 years.

\section{Methods}

\section{Study design and participants}

This non-interventional, cross-sectional clinical study was conducted in our Physical Medicine and Rehabilitation
Department. A total of 174 patients who were regularly admitted to the outpatient clinic of a tertiary care university hospital were included in the study. Patients were divided into two age groups: 18-64 years (group 1, $n=85$ [48.9\%]) and 65 years or older (group 2, $n=89$ [51.1\%]). The exclusion criteria were as follows: (i) patients whose medical records were incomplete and who were not taking medication or who had not attended for follow-up (defined as no visit to the outpatient clinic within the last 12 months); (ii) patients at the age of $<18$ years; (iii) patients with any diagnosis of psychiatric disorders, with cognitive dysfunction, and receiving psychiatric treatments; (iv) patients who required the assistance of a caregiver due to significant comorbid diseases, including stroke and advanced cancer; (v) patients diagnosed with fibromyalgia; (vi) pregnant women; (vii) prisoners, (viii) patients with communication problems and inability to read and understand the questionnaires. After the patients agreed to participate in the study, patients' sociodemographic (gender, age, educational status, marital status, occupational status, place of residence) and clinical (rheumatic diseases, duration of rheumatic disease, first application complaints before diagnosis, comorbid diseases, medications used) characteristics were recorded.

The diagnosis of rheumatoid arthritis (RA) was based on the American College of Rheumatology (ACR) criteria [9] and the diagnosis of ankylosing spondylitis (AS) was based on the modified New York criteria [10]. Patients were diagnosed with psoriatic arthritis (PsA) according to the classification criteria for psoriatic arthritis [11], gout according to the 2015 classification criteria for gout recommended by the ACR and the European League Against Rheumatism (EULAR) [12], and polymyalgia romatica (PMR) according to the 2012 EULAR/ ACR classification criteria [13]. Since no other rheumatic diseases were found in the study patients who met the inclusion criteria, they were not included in the study. The medications used to treat rheumatic diseases were categorized as follows: corticosteroids, non-steroidal antiinflammatory drugs (NSAIDs), disease-modifying antirheumatic drugs (DMARDs), biological drugs, colchicine, azathioprine, allopurinol. Information about having undergone orthopedic surgery for rheumatic diseases and the surgical area that required replacement surgery was also recorded.

\section{Ethics approval}

The study protocol was approved by the local Clinical Research Ethics Committee (Decision No.: 2020/147; Date 20 July 2020). Prior to evaluation, patients or their legal guardians were informed verbally and in writing about the nature of the study. Informed consents were signed at the time of enrollment in the study. All procedures performed in studies involving human participants 
conformed to the ethical standards of the institutional research committee and the 1964 Declaration of Helsinki and its subsequent amendments or comparable ethical standards.

\section{Assessment of quality of life}

Patients' quality of life was assessed using the first part of the Nottingham Health Profile (NHP), which was translated and validated into Turkish by Kucukdeveci et al. The internal consistency coefficients ranged from 0.56 to 0.87 and the test-retest reliability ranged from 0.70 to 0.88 [14]. The functional status of patients was measured by answering "yes" or "no" to 38 questions. The Nottingham Health Profile includes six domains: pain (8 items), emotional reaction (9 items), sleep (5 items), social isolation (5 items), physical activity (8 items), and energy (3 items). Each domain is rated on a 100-point scale, with a higher score indicating better quality of life. Each comment has a specific weight in the scoring. Examples of comments on the scale are the following: "I feel lonely," "I have difficulty going up and down stairs and steps," "I have difficulty sleeping," "I can not walk at all" [14]. This study's internal consistency coefficients (Cronbach $\alpha$ ) were calculated as 0.79 for energy, 0.69 for pain, 0.85 for emotional reaction, 0.78 for sleep, 0.84 for social isolation, and 0.82 for physical activity.

\section{Assessment of physical function}

Physical function was assessed using Health Assessment Questionnaire (HAQ) and the Bath Ankylosing Spondylitis Functional Index (BASFI). The HAQ assesses activities of daily living and physical function. It is a scale consisting of 20 items in eight parts. It is a selfadministered questionnaire, and the responses to each item range from "without any difficulty (0)" to "with some difficulty (1)," "with great difficulty (2)," and "unable to do (3)." In addition, the use of assistive devices and help from another person are also included in the scoring. The parts that make up the scale are dressing, arising, eating, walking, hygiene, reaching, gripping and tasks of daily living, and each section contains two or three items. Each section is scored separately and a single HAQ score is calculated from the average of the eight sections, which can range from 0 to 3 . The highest score among the items that make up each section is determined as the section score when scoring the sections. A Turkish study on the validity and reliability of the HAQ was conducted [15].

The BASFI is a self-administered questionnaire that measures the person's ability to perform 10 items of activities of daily living. It consists of ten items which are scored by visual analog score (VAS). The index score is given based on the average of the 10 items between 0 and 10 and ranges from "easy" to "impossible." A Turkish version is available $[16,17]$.

\section{Assessment of medication adherence}

Medication adherence of patients with rheumatic diseases was assessed using the Medication Adherence Report Scale (MARS). This is a five-item structured questionnaire designed to assess a range of nonadherent behaviors, including the tendency to avoid, forget or stop taking medication and the tendency to adjust or change the dose prescribed by the physician. Unlike other medication adherence scales with dichotomous responses, the number of items and range of response options in MARS-5 highlights the dynamic pattern of the medication adherence phenomenon. The items of the scale are to be answered on a five-point Likert scale ranging from (1) "always" to (5) "never." The cumulative score of MARS ranges from 5 to 25 . A higher score on MARS indicates a higher level of self-reported adherence to the corresponding medication and a decrease in score on MARS indicates incompatibility [18, 19]. The current study used the Turkish version of MARS, which was previously validated to measure treatment adherence for all chronic diseases requiring long-term medication. The internal consistency coefficient (.78) and overall item correlations (ranging from .35 to .71) in this study were similar to those in the original version [20]. The internal consistency coefficient (Cronbach $\alpha$ ) was also calculated using the baseline data. The MARS showed good internal consistency across study groups with Cronbach's $\alpha$-coefficients of .95.

\section{Statistical analysis}

The sample size was calculated using the program G*power (V3.1.7), with a minimum sample size of 67 participants at an $\alpha=0.05$ and a power of $80 \%$ for each group. While the data were analyzed with IBM SPSS V23, conformity to the normal distribution was tested using the tests Kolmogorov-Smirnov and Shapiro Wilk. The tests Mann-Whitney $U$ and Kruskal-Wallis were used to compare data that did not have a normal distribution. Finally, we assessed correlations between variables using the Spearman rho test and categorical data using the chi-square test. The significance level was set at $P \leq 0.05$.

\section{Results}

The participant recruitment scheme for the Strengthening the Reporting of Observational Studies in Epidemiology (STROBE) study is shown in Fig. 1. A total of 174 patients were included in the final analyzes. Of the 174 patients, 99 (56.9\%) were female and 75 (43.1\%) were male. The mean age of all recruited patients was $57.55 \pm$ 16.98 years. The mean duration of rheumatic disease 


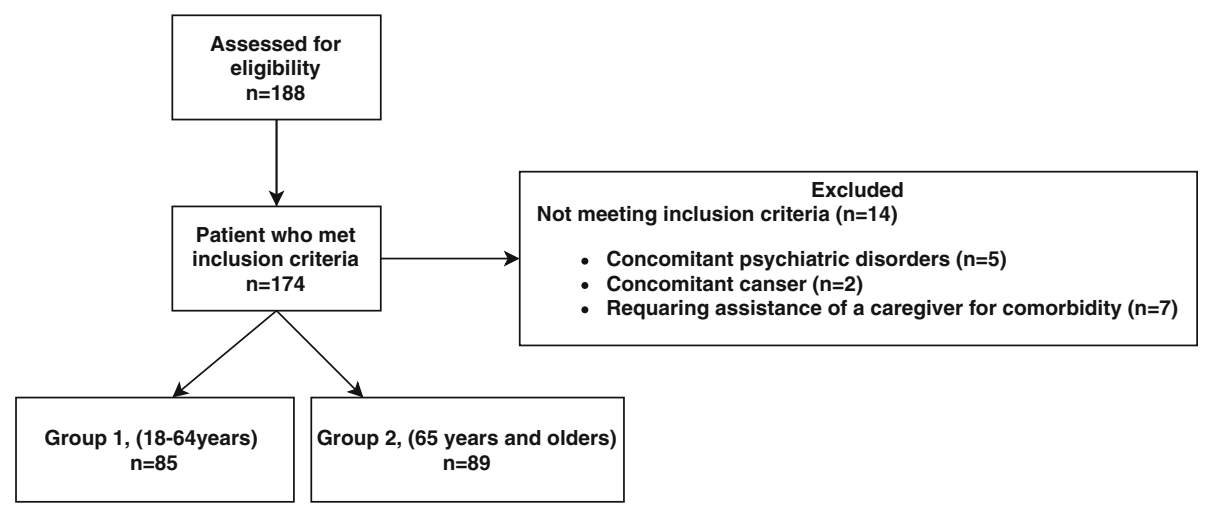

Fig. 1 The participant recruitment scheme

was $7 \pm 4.8$ years and the age at onset was $51.46 \pm 14.78$ years. A comparison of patient sociodemographic and clinical characteristics by age group is shown in Table 1 . The gender distribution differed significantly by age group $(P=0.024)$. The percentage of females in group 1 was $48.2 \%$ and $65.2 \%$ in group 2 . The occupational status also differed significantly by age group $(P<0.001)$. $48.2 \%$ of group 1 were employed and $57.3 \%$ of group 2 were housewives. Marital status varied significantly by age $(P<0.001)$. The percentage of married was $74.1 \%$ in group 1 and the percentage of separated/divorced/ widowed in group 2 was $28.1 \%$. There was no difference between groups 1 and 2 in terms of place of residence $(P$ $=0.459)$. In addition, rheumatic diseases, first application complaints before diagnosis, having undergone orthopedic surgery for rheumatic diseases, and the surgical area that required replacement surgery were found to differ significantly between these groups. Table 2 presents the comparison of the groups according to the medications used and comorbid diseases. There was a significant difference between groups 1 and 2 in terms of comorbid diseases and medications used. The prevalence of hypertension ( $77.2 \%$ vs. $78.9 \%)$, diabetes mellitus $(44.3 \%$ vs. $26.3 \%)$, coronary artery disease $(20.3 \%$ vs. $5.3 \%)$, osteoporosis $(29.1 \%$ vs. $10.5 \%)$, and psoriasis $(1.3 \%$ vs. \%15.3) was significantly higher in the 65 years or older $(\geq 65)$ age group (group 2$)(P=0.008)$. While the rate of use of medications for comorbid diseases was $27.1 \%$ in the $18-64$ age group (group 1), it was $88.8 \%$ in the 65 years or older $(\geq 65)$ age group (group 2) (Table 2).

The comparisons of HAQ, BASFI, and NHP by age groups are presented in Table 3 . The median values of HAQ $(P=0.003)$ and BASFI $(P=0.001)$ differed significantly between groups 1 and 2 . While the HAQ median value was 0.15 in group 1 , it was 0.3 in group 2 . BASFI group 1 median value was 1.7 , while it was 4.9 in group 2. Quality of life (NHP) subscales were also compared; the median values of patients' NHP subscales (pain, emotional reaction, sleep, physical activity, energy) showed a significant difference, except for social isolation $(P=0, P=0.005, P=0, P=0, P=0, P=0.024$, respectively). Median pain values differ according to age groups $(\mathrm{P}=0)$. While the median value in the group 1 was 12.91 , it was 29.4 in the group 2. Emotional median values differ according to age groups $(P=0.005)$. While the median value in the group 1 was 0 , it was 16.21 in the group 2. Median sleep values differ according to age groups $(P=0)$. While the median value in the group 1 was 0 , it was 43.36 in the group 2 . The median values of social isolation do not differ according to age groups $(P$ $=0.062$ ). While the median value was 0 in the group 1 , it was 0 in the group 2 . The median values of physical activity differ according to age groups $(P=0)$. While the median value in the group 1 was 10.57 , it was 42.1 in the group 2 . The median energy values differ according to age groups $(P=0.024)$. While the median value in the group 1 was 0 , it was 24 in the group 2 . Moreover, MARS median values differed significantly between these groups $(P=0.004)$; the median value was 18 in group 1 and 16 in group 2 (Table 3 ).

The comparisons of HAQ, BASFI, and NHP by rheumatic diseases within age groups are shown in Table 4. There was no significant difference in scale scores according to rheumatic diseases between group 1 and group 2 . In patients with ankylosing spondylitis, pain, physical activity, and energy scores differed significantly between groups 1 and 2. Pain scores differ in age groups in patients with ankylosing sondylitis $(P=0.045)$. While the median score of the group 1 was 23.4, the median score of the group 2 was 12.91 . Similarly, physical activity $(P=0.028)$ and energy scores $(P=0.043)$ differ according to age groups. Physical activity and energy scores were higher in elderly patients (in group 2). In patients with rheumatoid arthritis, scores for pain, emotional reaction, sleep, physical activity, and HAQ also showed significant difference between groups 1 and 2; patients in group 2 had a higher median score. There were no significant age-related differences in the scale scores of patients with other rheumatic diseases (Table 4). 
Table 1 Comparison of patient sociodemographic and clinical characteristics by age group

\begin{tabular}{|c|c|c|c|c|}
\hline & $\begin{array}{l}\text { 18-64 years } \\
\text { (group1, } n=85)^{*} \\
n(\%)\end{array}$ & $\begin{array}{l}\geq 65 \text { years } \\
\text { (group } 2, n=89)^{*} \\
n(\%)\end{array}$ & $\begin{array}{l}\text { Total } \\
n(\%)\end{array}$ & $P$ \\
\hline \multicolumn{5}{|l|}{ Gender } \\
\hline Female & $41(48.2)$ & $58(65.2)$ & $99(56.9)$ & \multirow[t]{2}{*}{0.024} \\
\hline Male & $44(51.8)$ & $31(34.8)$ & $75(43.1)$ & \\
\hline \multicolumn{5}{|l|}{ Occupational status } \\
\hline Housewife & $30(35.3)$ & $51(57.3)$ & $81(46.6)$ & \multirow[t]{3}{*}{$<0.001$} \\
\hline Employed & $41(48.2)$ & $14(15.7)$ & 55 (31.6) & \\
\hline Unemployed & $14(16.5)$ & $24(27)$ & $38(21.8)$ & \\
\hline \multicolumn{5}{|l|}{ Maritalstatus } \\
\hline Single/never married & $18(21.2)$ & $0(0)$ & $18(10.3)$ & \multirow[t]{3}{*}{$<0.001$} \\
\hline Married & $63(74.1)$ & $64(71.9)$ & $127(73)$ & \\
\hline Separated/divorced/widowed & $4(4.7)$ & $25(28.1)$ & $29(16.7)$ & \\
\hline \multicolumn{5}{|l|}{ Place of residence } \\
\hline Urban & $75(88.2)$ & $74(83.1)$ & $149(85.6)$ & \multirow[t]{2}{*}{0.459} \\
\hline Rural & $10(11.8)$ & $15(16.9)$ & $25(14.4)$ & \\
\hline \multicolumn{5}{|l|}{ Rheumatic diseases } \\
\hline Ankylosing spondylitis & $39(45.9)$ & $13(14.6)$ & $52(29.9)$ & \multirow[t]{5}{*}{$<0.001$} \\
\hline Rheumatoid arthritis & $31(36.5)$ & $62(69.7)$ & $93(53.4)$ & \\
\hline Gout & $4(4.7)$ & $8(9)$ & $12(6.9)$ & \\
\hline Polymyalgia rheumatica & $2(2.4)$ & $2(2.2)$ & $4(2.3)$ & \\
\hline Psoriatic arthritis & $9(10.6)$ & $4(4.5)$ & $13(7.5)$ & \\
\hline \multicolumn{5}{|c|}{ First application complaints before diagnosis } \\
\hline Knee pain & $8(9.4)$ & $14(15.7)$ & $22(12.6)$ & \multirow[t]{7}{*}{$<0.001$} \\
\hline Arthralgia & $12(14.1)$ & $12(13.5)$ & $24(13.8)$ & \\
\hline Hip pain & $19(22.4)$ & $0(0)$ & $19(10.9)$ & \\
\hline Lower back and hip pain & $17(20)$ & $7(7.9)$ & $24(13.8)$ & \\
\hline Hand polyarthritis & $23(27.1)$ & $44(49.4)$ & $67(38.5)$ & \\
\hline Metatarsophalangeal arthritis & $3(3.5)$ & $11(12.4)$ & $14(8)$ & \\
\hline Rash/dactylitis & $3(3.5)$ & $1(1.1)$ & $4(2.3)$ & \\
\hline \multicolumn{5}{|c|}{ Having undergone orthopedic surgery for rheumatic diseases } \\
\hline Yes & $2(2.4)$ & $16(18)$ & $18(10.3)$ & \multirow[t]{2}{*}{0.002} \\
\hline No & $83(97.6)$ & $73(82)$ & $156(89.7)$ & \\
\hline \multicolumn{5}{|c|}{ The surgical area that required replacement surgery } \\
\hline Knee & $1(1.2)$ & $7(7.9)$ & $8(4.6)$ & \multirow[t]{5}{*}{0.005} \\
\hline Hip & $0(0)$ & $7(7.9)$ & $7(4)$ & \\
\hline Femur & $0(0)$ & $2(2.2)$ & $2(1.1)$ & \\
\hline Ankle & $1(1.2)$ & $0(0)$ & $1(0.6)$ & \\
\hline No & $83(97.6)$ & $73(82)$ & $156(89.7)$ & \\
\hline \multicolumn{5}{|l|}{ Comorbid diseases } \\
\hline Yes & $23(27.1)$ & $80(89.9)$ & $103(59.2)$ & \multirow[t]{2}{*}{$<0.001$} \\
\hline No & $62(72.9)$ & $9(10.1)$ & 71 (40.8) & \\
\hline
\end{tabular}

$P \leq 0.05,{ }^{*} n$ (\%)

$P \leq 0.05$ is considered significant 
Table 2 Comparison of the groups according to the medications used and comorbid diseases

\begin{tabular}{|c|c|c|c|c|c|}
\hline & & $\begin{array}{l}\text { 18-64 years (group 1, } \\
n=85) n(\%)\end{array}$ & $\begin{array}{l}\geq 65 \text { years (group } 2, \\
n=89) n(\%)\end{array}$ & Test statistics & $P$ \\
\hline & Corticosteroids & $8(9.4)$ & $7(7.9)$ & $x^{2}=85.882$ & $<0.001$ \\
\hline & NSAIDs & $56(65.9)$ & $46(51.7)$ & & \\
\hline & DMARDS & $39(45.9)$ & $27(30.3)$ & & \\
\hline \multirow[t]{7}{*}{ Medicationsused } & Biological drugs & $50(58.8)$ & $55(61.8)$ & & \\
\hline & $\begin{array}{l}\text { Medications for comorbid diseases } \\
\text { (nonrheumatic treatments) }\end{array}$ & $23(27.1)$ & $79(88.8)$ & & \\
\hline & Colchicine & $7(8.2)$ & $14(15.7)$ & & \\
\hline & Azothiopurine & $2(2.4)$ & $2(2.2)$ & & \\
\hline & Allopurinol & $0(0)$ & $7(7.9)$ & & \\
\hline & Hypertension & $15(78.9)$ & $61(77.2)$ & $x^{2}=15.515$ & 0.008 \\
\hline & Diabetes mellitus & $5(26.3)$ & $35(44.3)$ & & \\
\hline \multirow[t]{3}{*}{ Comorbid diseases } & Coronary artery disease & $1(5.3)$ & $16(20.3)$ & & \\
\hline & Osteoporosis & $2(10.5)$ & $23(29.1)$ & & \\
\hline & Psoriasis & $3(15.8)$ & $1(1.3)$ & & \\
\hline
\end{tabular}

$P \leq 0.05$ NSAIDs non-steroidal anti-inflammatory drugs, DMARDS disease-modifying anti-rheumatic drugs

$X^{2}$ chi-square test

$P \leq 0.05$ is considered significant

The correlation analysis of HAQ, BASFI, and NHP by age group is shown in Table 5 . While a moderately strong positive correlation was found between the HAQ and the NHP subdimensions, there was a moderately strong negative correlation between the HAQ and the MARS in group 1. There was also a strong positive correlation between the BASFI and the pain and physical activity subdimensions of the NHP, and a moderately strong positive correlation between the BASFI and the other subdimensions of the NHP. At the same time, a significant negative correlation was found between MARS and all dimensions. A similar result was obtained for group 2 (Table 5).

\section{Discussion}

As in the whole world, a gradual increase in the incidence of rheumatic diseases has been observed in our country due to an increase in the elderly population [21, 22]. The present study results suggest that rheumatic diseases vary by age and that elderly patients have a higher need for orthopedic surgery due to rheumatic diseases, a higher prevalence of comorbid diseases, and a higher rate of medication use but a lower rate of DMAR D use. Our study showed a positive correlation between physical function and quality of life in both age groups. It was also shown that the treatment adherence rating scale we used to assess treatment adherence negatively

Table 3 Comparisons of HAQ, BASFI, and NHP by age groups

\begin{tabular}{|c|c|c|c|c|c|c|c|}
\hline & \multicolumn{2}{|c|}{ 18-64 years (group 1) } & \multicolumn{2}{|c|}{$\geq 65$ years (group 2 ) } & \multicolumn{2}{|l|}{ Total } & \multirow[t]{2}{*}{$P^{*}$} \\
\hline & Mean & Median & Mean & Median & Mean & Median & \\
\hline HAQ & $0.21 \pm 0.237$ & $0.15(0-1)$ & $0.46 \pm 0.883$ & $0.3(0-7)$ & $0.37 \pm 0.722$ & $0.2(0-7)$ & 0.003 \\
\hline BASFI & $1.91 \pm 1.798$ & $1.7(0.1-7.2)$ & $4.8 \pm 0.957$ & $4.9(3.4-6.1)$ & $2.35 \pm 1.988$ & $1.8(0.1-7.2)$ & 0.001 \\
\hline NHP pain & $21.367 \pm 27.337$ & $12.91(0-100)$ & $41.544 \pm 32.118$ & $29.4(0-100)$ & $31.688 \pm 31.463$ & $18.74(0-100)$ & 0.000 \\
\hline NHP emotional reaction & $11.853 \pm 18.063$ & $0(0-76.25)$ & $22.072 \pm 24.905$ & $16.21(0-86.25)$ & $17.08 \pm 22.364$ & $7.15(0-86.25)$ & 0.005 \\
\hline NHP sleep & $20.728 \pm 29.303$ & $0(0-87.63)$ & $42.525 \pm 39.075$ & $43.36(0-100)$ & $31.877 \pm 36.235$ & $12.57(0-100)$ & 0.000 \\
\hline NHP social isolation & $10.829 \pm 15.836$ & $0(0-81.64)$ & $19.416 \pm 27.905$ & $0(0-100)$ & $15.221 \pm 23.16$ & $0(0-100)$ & 0.062 \\
\hline NHPphysical activity & $16.78 \pm 23.827$ & $10.57(0-88.7)$ & $35.025 \pm 25.441$ & $42.1(0-88.7)$ & $26.112 \pm 26.24$ & $11.2(0-88.7)$ & 0.000 \\
\hline NHP energy & $23.708 \pm 33.106$ & $0(0-100)$ & $36.164 \pm 38.408$ & $24(0-100)$ & $30.079 \pm 36.353$ & $24(0-100)$ & 0.024 \\
\hline MARS & $17.2 \pm 4.954$ & $18(5-25)$ & $14.787 \pm 5.546$ & $16(5-25)$ & $15.966 \pm 5.388$ & $17(5-25)$ & 0.004 \\
\hline
\end{tabular}

$P \leq 0.05$ HAQ Health Assessment Questionnaire, BASFI Bath Ankylosing Spondylitis Functional Index, NHP Nottingham Health Profile, MARS Medication Adherence Rating Scale

*Mann-Whitney $U$ test

$P \leq 0.05$ is considered significant 


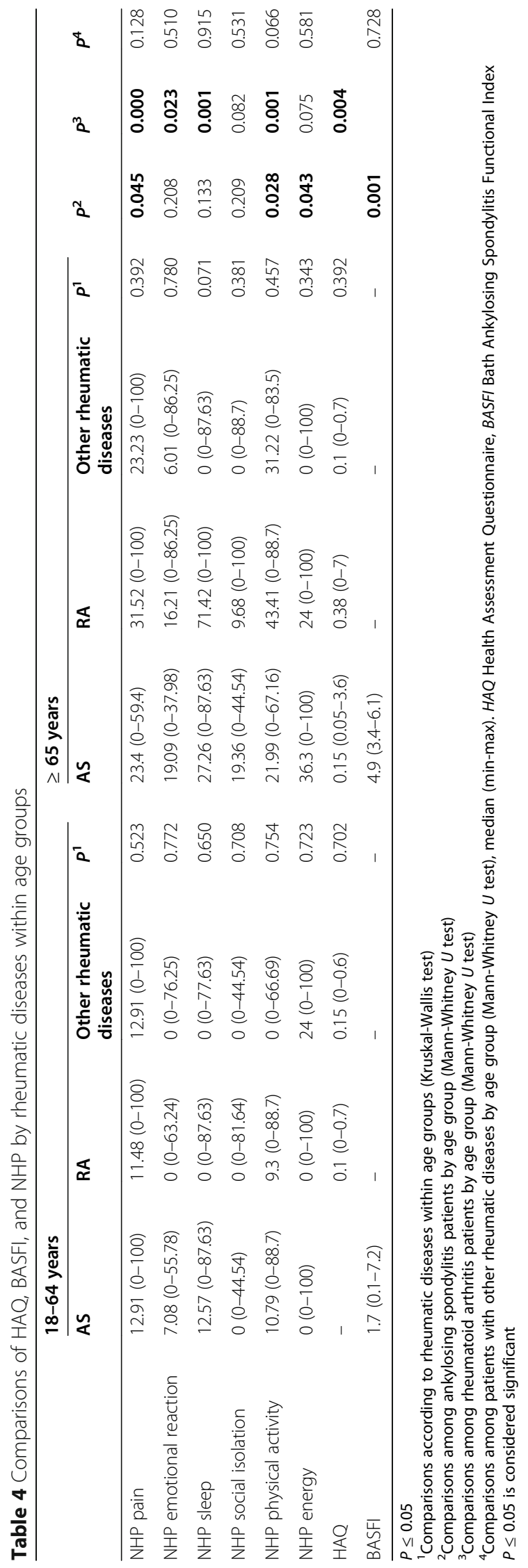


Table 5 Correlation analysis of HAQ, BASFI, and NHP by age group

\begin{tabular}{|c|c|c|c|c|}
\hline Group & Scale & HAQ & BASFI & MARS \\
\hline \multirow[t]{9}{*}{ 18-64 years (group 1) } & HAQ & & & $-0.592^{* *}$ \\
\hline & BASFI & & & $-0.670^{* *}$ \\
\hline & NHP pain & $0.750^{* *}$ & $0.954^{* *}$ & $-0.750^{* *}$ \\
\hline & NHP emotional reaction & $0.462^{* *}$ & $0.663^{* *}$ & $-0.602^{* *}$ \\
\hline & NHP sleep & $0.410^{* *}$ & $0.643^{* *}$ & $-0.599^{* *}$ \\
\hline & NHP social isolation & $0.396^{* *}$ & $0.442^{* *}$ & $-0.520^{* *}$ \\
\hline & NHP physical activity & $0.633^{* *}$ & $0.715^{* *}$ & $-0.647^{* *}$ \\
\hline & NHP energy & $0.553^{* *}$ & $0.561^{* *}$ & $-0.634^{* *}$ \\
\hline & MARS & $-0.592^{* *}$ & $-0.670^{* *}$ & \\
\hline \multirow[t]{9}{*}{$\geq 65$ years (group 2) } & $\mathrm{HAQ}$ & & & $-0.622^{* *}$ \\
\hline & BASFI & & & -0.643 \\
\hline & NHP pain & $0.726^{* *}$ & $0.863^{*}$ & $-0.916^{* *}$ \\
\hline & NHP emotional reaction & $0.648^{* *}$ & $0.756^{*}$ & $-0.832^{* *}$ \\
\hline & NHP sleep & $0.619^{* *}$ & $0.863^{*}$ & $-0.705^{* *}$ \\
\hline & NHP social isolation & $0.565^{* *}$ & -0.158 & $-0.591^{* *}$ \\
\hline & NHP physical activity & $0.658^{* *}$ & $0.973^{* *}$ & $-0.827^{* *}$ \\
\hline & NHP energy & $0.715^{* *}$ & 0.422 & $-0.765^{* *}$ \\
\hline & MARS & $-0.622^{* *}$ & -0.643 & \\
\hline
\end{tabular}

${ }^{*} P \leq 0.05$; ${ }^{*} P<0.001$ HAQ Health Assessment Questionnaire, BASFI Bath Ankylosing Spondylitis Functional Index, MARS Medication Adherence Rating Scale $P \leq 0.05$ is considered significant

correlated with physical activity and quality of life scores. Individuals with poor treatment adherence had worse physical function and quality of life.

The prevalence and clinical signs of rheumatic diseases can vary by age. Rheumatoid arthritis is one of the most common rheumatic diseases. While the prevalence of PMR and crystal arthritis increases with aging, the prevalence of spondyloarthropathies and connective tissue diseases decreases. In accordance with the literature data, our study determined that RA is the most common rheumatic disease in the elderly, while spondyloarthropathy is the most common rheumatic disease in the young. Males are in the majority in young people, while females predominate in the elderly [22-24]. The difference between groups in terms of occupational status was similar to that reported in the literature, with a greater proportion of employed patients in the young, while housewives accounted for a greater proportion in the elderly [24]. The prevalence of comorbid diseases is higher in the elderly. Polypharmacy, a common problem in the elderly due to a higher prevalence of comorbid diseases, may complicate treatment planning for rheumatic diseases. Drug interactions, side effects, and contraindications due to hepatic and renal dysfunction may limit treatment options. Rheumatic diseases can lead to serious consequences such as functional disability and physical dependence in the elderly if not diagnosed and treated appropriately on time. Because effective treatment reduces morbidity and mortality, factors such as a patient's comorbid diseases and medication adherence, as well as the physician's experience and risk tolerance, are critical to treatment planning. Previous studies have shown that synthetic DMARDs are used less frequently or at lower doses and that physicians are more reluctant to prescribe biological medications in elderly RA patients compared with young patients [22, 24-28]. In our study, we compared the young (18-64 years) and elderly ( $\geq 65$ years) groups in terms of the medications used. Consistent with previous studies, we detected a significant difference in the use of DMARDs and comorbid disease medications. The rate of use of medications for comorbid diseases was $88.8 \%$, DMARDs $30.3 \%$ and biological agents $61.8 \%$ in the elderly ( $\geq 65$ years) group. Rheumatoid arthritis, which we identified as the most common rheumatic disease in the elderly, is a systemic inflammatory disease that can lead to chronic synovitis and joint damage. Although our study mainly involved the small joints of the hands and feet, knee and hip joints were also affected; our findings are consistent with those in the literature [29]. Orthopedic surgery of the knee and hip joints may be required due to joint destruction and secondary osteoarthritis leading to functional limitations and decreased quality of life. Reportedly, $4-12 \%$ of RA patients undergo knee and hip joint replacement surgery. The need for joint replacement implantation due to joint destruction may increase 
in RA patients as they age, disease duration increases, and no effective treatment is available due to advanced age and comorbid diseases. In our study, a significant difference was found between the study groups in having undergone orthopedic surgery for rheumatic diseases and the surgical area that required replacement surgery. The frequency of knee and hip surgical areas that required replacement surgery in the elderly group was similar to that reported in the literature [29-31]. The goals of treatment of rheumatic diseases in the elderly should be similar to those in the young. It should aim to achieve remission or at least a reduction in disease activity as soon as possible, prevent pain and long-term damage, and avoid loss of function in daily activities, thus improving quality of life. Studies have shown that a greater burden of comorbidities, more difficult treatment planning, immune dysfunction, and inadequate rehabilitation are associated with worse functional outcomes and quality of life in the elderly. The prevalence of hypertension (77.2\% vs. $78.9 \%)$, diabetes mellitus (44.3\% vs. $26.3 \%)$, coronary artery disease $(20.3 \%$ vs. $5.3 \%)$, osteoporosis ( $29.1 \%$ vs. $10.5 \%)$, and psoriasis ( $1.3 \%$ vs. $15.3 \%)$ was significantly higher in those 65 years or older $(P=0.008)$ in the current study. Besides, while the rate of use of medications for comorbid diseases was $27.1 \%$ in the 18-64 age group, it was $88.8 \%$ in those 65 years and older. A study comparing young and elderly RA patients found that comorbidities such as hypertension, diabetes mellitus, ischemic heart disease, cardiovascular accidents, and osteoporosis were more common in elderly patients [24]. In the literature, elderly patients were found to have poorer functional status and negatively impacted quality of life with higher HAQ scores [24, 32, 33]. The present study results showed age-related differences in HAQ and BASFI scores, with elderly patients scoring higher; there was also a positive correlation between physical function and quality of life.

Non-adherence to medical therapy has been associated with increased disease activity, impaired quality of life, and increased health care costs and mortality. Studies examining medication adherence have reported adherence rates of 30 to $80 \%$ for RA and 3 to $76 \%$ for systemic lupus erythematosus, depending on the assessment method. Suboptimal adherence has also been associated with poorer treatment response and disease exacerbation [34, 35]. Although there are several scales for assessing treatment adherence, there is still no consensus on the best assessment method. In most studies investigating treatment adherence in rheumatic diseases, a self-report scale was preferred and a single scale was used. It has been determined that inadequate treatment adherence significantly impacts medication effectiveness in chronic diseases, impairs functionality, and worsens quality of life [36]. A study of treatment adherence in RA patients highlighted the difficulty of assessing treatment adherence and the need for objective measurements [37]. In a study of 140 RA patients, in which treatment adherence was assessed using the Morisky scale, low and moderate treatment adherence was found to be $90.6 \%$ and $9.4 \%$, respectively [38]. Literature reports that high quality of life is present in individuals with high treatment adherence [8]. A study investigating the relationship between treatment adherence and quality of life in patients with various rheumatic diseases emphasized that individuals with high treatment adherence have a better quality of life [39]. In our study, in which treatment adherence was assessed using the MARS scale, we found a significant difference between young and elderly patients, with young patients having higher treatment adherence. Consistent with the literature, our study found a correlation between treatment adherence, physical function, and quality of life.

\section{Conclusions}

Elderly and younger patients with rheumatic diseases have different demographic and clinical characteristics. Rheumatic diseases, first complaints before diagnosis, having undergone orthopedic surgery for rheumatic diseases, comorbid diseases, and use of medications for comorbid diseases (non-rheumatic treatments) differed significantly by age in the current study. The prevalence of comorbid diseases and the rate of use of medications for comorbid diseases (non-rheumatic treatments) is higher in elderly patients. We detected a significant difference in the use of DMARDs. The rate of use of DMARDs was $30.3 \%$ in the elderly group. The rate of use of biological agents was $61.8 \%$ in the elderly group and the biological agents was used for the rheumatic diseases (rheumatoid arthritis, ankylosing spondylitis and psoriatic arthritis) at the appropriate treatment dose. Physical function and quality of life are more affected by rheumatic diseases, and treatment adherence is poorer in the elderly. Our study showed a positive correlation between physical function and quality of life in both age groups. It also showed that the treatment adherence rating scale we used to assess treatment adherence had a negative correlation with physical function and quality of life scores, with individuals with poor treatment adherence having worse physical function and quality of life.

\section{Limitation of the study}

The present study had some limitations. First, the limited number of elderly patients and the fact that the study was conducted in a single center were limitations of our study. Secondly, only patients with RA, AS, gout, PMR, and PsA were included in the study. Other rheumatic diseases such as SLE, scleroderma, and inflammatory myopathies were not found in the study patients who met the inclusion criteria and for this reason were not included in the study. 


\section{Abbreviations}

WHO: World Health Organization; RA: Rheumatoid arthritis; AS: Ankilozan spondylitis; PSA: Psoriatic arthritis; ACR: American College of Rheumatology; EULAR: European League Against Rheumatism; PMR: Polimyalgia romatica; NSAIDs: Nonsteroidal anti-inflammatory drugs; DMARDS: Disease-modifying anti-rheumatic drugs; HAQ: Health Assessment Questionnaire; BASFI: Bath Ankylosing Spondylitis Functional Index; NHP: Nottingham Health Profile; MARS: Medication Adherence Rating Scale

\section{Acknowledgements}

The authors would like to thank all the participants of this study. We thank Hasan Sultanoğlu, Düzce University School of Medicine, Department of Emergency Medicine for his valuable contributions for statistical analysis.

\section{Authors' contributions}

TES, BA, and ÖFM: data collection, writing, and supervision. TES and SA: statistical analyses, supervision, critical analyses, and data collection. All authors have read and approved the final manuscript.

\section{Funding}

We have no funding sources that supported our work.

\section{Availability of data and materials}

The datasets used and/or analyzed during the current study are available from the corresponding author on reasonable request.

\section{Declarations}

\section{Ethics approval and consent to participate}

The study was conducted in accordance with the Declaration of Helsinki and the study protocol was approved by the Ethical Committee of Düzce University Medical School (Decision No.: 2020/147; Date 20 July 2020) Written informed consent was given from all participants.

\section{Consent for publication}

$$
\text { Not applicable }
$$

\section{Competing interests}

The authors declare that they have no competing interests.

\section{Received: 12 August 2021 Accepted: 28 September 2021}

\section{Published online: 20 December 2021}

\section{References}

1. Forouzanfar MH, Afshin A, Alexander LT, Anderson HR, Bhutta ZA, Biryukov S, Carrero JJ (2016) Global, regional, and national comparative risk assessment of 79 behavioural, environmental and occupational, and metabolic risks or clusters of risks, 1990-2015: a systematic analysis for the Global Burden of Disease Study 2015. The Lancet 388(10053):1659-1724. https://doi.org/10.1016/S0140-6736(16)31679-8

2. Sultanoğlu H, Sultanoğlu TE (2021) Evaluation of elderly patients in adult suicide cases admitted to the emergency department. Journal of forensic and legal medicine 77:102103. https://doi.org/10.1016/j.jflm.2020.102103

3. Turkish Statistical Institute Suicidestatistics (2018) Turkey, Ankara http:// www.turkstat.gov. tr/PrelstatistikTablo.do?istab_id=106. Accessed 21 April 2021.

4. Lahaye C, Tatar Z, Dubost J, Tournadre A, Soubrier M (2019) Management of inflammatory rheumatic conditions in the elderly. Rheumatology 58(5):748764. https://doi.org/10.1093/rheumatology/key165

5. McElhaney JE, Effros RB (2009) Immunosenescence: what does it mean to health outcomes in older adults? Curr Opin Immunol 21(4):418-424. https:// doi.org/10.1016/j.coi.2009.05.023

6. Bressler R, Bahl JJ (2003) Principles of drug therapy for the elderly patient. Mayo Clin Proc 78(12):1564-1577. https://doi.org/10.4065/78.12.1564

7. World Health Organisation. Global Status Report on Noncommunicable Diseases (2010) Switzerland, Geneva .http://www.who.int/nmh/publications/ ncd_report2010/en/ Accessed 21 April 2021.

8. Ágh T, Dömötör P, Bártfai Z, Inotai A, Fujsz E, Mészáros Á (2015) Relationship between medication adherence and health related quality of life in subjects with COPD: a systematic review. Respir Care 60:297-303. https://doi.org/1 $0.4187 /$ respcare.03123
9. Aletaha D, Neogi T, Silman AJ, Felson DT, Bingham CO, Birnbaum NS, Burmester GR, Bykerk VP, Cohen MD, Combe B, Costenbader KH, Dougados M, Emery P, Ferraccioli G, Hazes JMW, Hobbs K, Huizinga TWJ, Kavanaugh A, Kay J, Kvien TK, Laing T, Mease P, Ménard HA, Moreland LW, Naden RL, Pincus T, Smolen JS, Biernat ES, Symmons D, Tak PP, Upchurch KS, Vencovský J, Wolfe F, Hawker G (2010) 2010 Rheumatoid arthritis classification criteria: an American College of Rheumatology/European League Against Rheumatism collaborative initiative. Ann Rheum Dis. 69(9): 1580-1588. doi: https://doi.org/10.1002/art.27584

10. Linden SVD, Valkenburg HA, Cats A (1984) Evaluation of diagnostic criteria for ankylosing spondylitis. Arthritis Rheum 27(4):361-368. https://doi.org/1 0.1002/art.1780270401

11. Taylor W, Gladman D, Helliwell P, Marchesoni A, Mease P, Mielants H (2006) Classification criteria for psoriatic arthritis: development of new criteria from a large international study. Arthritis Rheum 54(8):2665-2673. https://doi. org/10.1002/art.21972

12. Neogi $T$, Jansen $T L$, Dalbeth N Fransen J, Schumacher HR, Berendsen D, Brown M, Choi H, Edwards NL, Janssens HJEM, Lioté F, Naden RP, Nuki G, Ogdie A, Ruiz FP, Saag K, Singh JA, Sundy JS, Tausche AK, Mellado JV, Yarows SA, Taylor WJ (2015) 2015 Gout classification criteria: an American College of Rheumatology/European League Against Rheumatism collaborative initiative. Ann Rheum Dis. 74(10):1789-1798. doi: https://doi. org/10.1002/art.39254

13. Dasgupta B, Cimmino MA, Kremers HM, Schmidt WA, Schirmer M, Salvarani C, Bachta A, Dejaco C, Duftner C, Jensen HS, Duhaut P, Poór G, Kaposi NP, Mandl P, Balint PV, Schmidt Z, lagnocco A, Nannini C, Cantini F, Macchioni P, Pipitone N, Amo MD, Frigolé GE, Cid MC, Taboada VMM, Nordborg E, Direskeneli H, Aydin SZ, Ahmed K, Hazleman B, Silverman B, Pease C, Wakefield RJ, Luqmani R, Abril A, Michet CJ, Marcus R, Gonter N, Maz M, Carter RE, Crowson CE, Matteson EL (2012) Provisional Classification Criteria for Polymyalgia Rheumatica: A European League Against Rheumatism/ American College of Rheumatology Collaborative Initiative. Ann Rheum Dis. 71(4):484-492. https://doi.org/10.1002/art.34356

14. Küçükdeveci AA, McKenna SP, Kutlay S, Gursel Y, Whalley D, Arasıl T (2000) The development and psychometric assessment of the turkish version of the Nottingham health profile. International Journal of Rehabilitation Research. 23(1):31-38. https://doi.org/10.1097/00004356-200023010-00004

15. Küçükdeveci AA, Sahin H, Ataman S, Griffiths B, Tennant A (2004) Issues in cross-cultural validity: example from the adaptation, reliability, and validity testing of a Turkish version of the Stanford Health Assessment Questionnaire. Arthritis Rheum 51(1):14-19. https://doi.org/10.1002/art.20091

16. Zochling J (2011) Measures of symptoms and disease status in ankylosing spondylitis: Ankylosing Spondylitis Disease Activity Score (ASDAS), Ankylosing Spondylitis Quality of Life Scale (ASQoL), Bath Ankylosing Spondylitis Disease Activity Index (BASDAI), Bath Ankylosing Spondylitis Functional Index (BASFI), Bath Ankylosing Spondylitis Global Score (BAS-G), Bath Ankylosing Spondylitis Metrology Index (BASMI), Dougados Functional Index (DFI), and Health Assessment Questionnaire for the Spondylarthropathies(HAQ-S). Arthritis Care Res (Hoboken). 63(11):47-58. doi: https://doi.org/10.1002/acr.20575

17. Yanık B, Gürsel YK, Kutlay S, Ay S, Elhan AH (2005) Adaptation of the Bath Ankylosing Spondylitis Functional Index to the Turkish population, its reliability and validity: functional assessment in AS. Clin Rheumatol. 24(1): 41-47. https://doi.org/10.1007/s10067-004-0968-6

18. Chan AHY, Horne R, Hankins M, Chisari C (2019) The medication adherence report scale: a measurement tool for eliciting patients' reports of nonadherence. Br J Clin Pharmacol 86(7):1281-1288 doi.org/10.1111/bcp.14193

19. Stirratt MJ, Dunbar-Jacob J, Crane HM (2015) Self-report measures of medication adherence behavior: recommendations on optimal use. Transl Behav Med 5(4):470-482 doi.org/10.1007/s13142-015-0315-2

20. Sen ET, Berk OS, Sindel D (2019) The validity and reliability study ofthe Turkish adaptation of medical adherence report scale. J Ist Faculty Med 82(1):52-61. https://doi.org/10.26650/iuitfd.413637

21. Kato E, Sawada T, Tahara K, Hayashi H, Tago M, Mori H, Nishino J, Matsui T, Tohma S (2017) The age at onset of rheumatoid arthritis is increasing in Japan: a nation wide database study. Int J Rheum Dis 20(7):839-845. https:// doi.org/10.1111/1756-185X.12998

22. Ruban TN, Jacob B, Pope JE, Keystone EC, Bombardier C, Kuriya B (2016) The influence of age at disease onset on disease activity and disability: results from the Ontario Best Practices Research Initiative. Clin Rheumatol 35(3): 759-763. https://doi.org/10.1007/s10067-015-3031-x 
23. De Leonardis F, Govoni M, Colina M, Brushi M, Trotta F (2007) Elderly onset gout: a review. Rheumatol Int. 28(1):1-6. https://doi.org/10.1007/s00296-0070421-7

24. Tan TC, Gao X, Thong BY (2017) TTSH Rheumatoid Arthritis Study Group. Comparison of elderly- and young onset rheumatoid arthritis in an Asian cohort. Int J Rheum Dis 20(6):737-745. https://doi.org/10.1111/1756-185X.12 861

25. Ranganath V, Maranian $P$, Elashoff D, Woodworth T, Khanna D, Hahn T, Sarkisian C, Kremer JM, Furst DE, Paulus HE (2013) Comorbidities are associated with poorer outcomes in community patients with rheumatoid arthritis. Rheumatology (Oxford) 52:1809-1817. doi: /https://doi.org/10.1093/ rheumatology/ket224

26. Listing J, Kekow J, Manger B, Burmester G, Pattloch D, Zink A, Strangfeld A (2015) Mortality in rheumatoid arthritis: the impact of disease activity, treatment with glucocorticoids, TNFa inhibitors and rituximab. Ann Rheum Dis 74:415-421. https://doi.org/10.1136/annrheumdis-2013-204021

27. Burn E, Edwards CJ, Murray DW (2019) Lifetime risk of knee and hip replacement following a diagnosis of RA: findings from a cohort of 1396 patients from England. Rheumatology (Oxford). 58:1950-1954. doi: https:// doi.org/10.1093/rheumatology/kez143

28. Freitas R, Godinho F, Madeira N, Fernandes BM, Costa F, Santiago M (2020) Safety and effectiveness of biologic disease-modifying antirheumatic drugs in older patients with rheumatoid arthritis: a prospective cohort study. Drugs\&Aging 37(12):899-907. https://doi.org/10.1007/s40266-020-00801-x

29. Fleischmann R, lqbal I (2007) Risk: benefit profile of etanercept in elderly patients with rheumatoid arthritis, ankylosing spondylitis or psoriatic arthritis. Drugs Aging 24:239-254. https://doi.org/10.2165/00002512-200724 030-00005

30. Smolen JS, Aletaha D, McInnes IB (2016) Rheumatoid arthritis. Lancet. 388(10055):2023-2038. https://doi.org/10.1016/S0140-6736(16)30173-8

31. Nishino J, Tanaka S, Matsui T (2009) Prevalence of joint replacement surgery in rheumatoid arthritis patients: cross-sectional analysis in a large observational cohort in Japan. Mod Rheumatol 19:260-264. https://doi.org/1 0.3109/s10165-009-0163-3

32. Redeker I, Callhoff J, Hoffmann F, Marschall U, Haibel H, Sieper J, Poddubnyy D (2020) The prevalence and impact of comorbidities on patients with axial spondyloarthritis: results from a nationwide population-based study. Arthritis research \& therapy 22(1):1-11. https://doi.org/10.1186/s13075-020-02301-0

33. Carmona L, Ballina J, Gabriel R, Laffon A on behalf of the EPISER Study Group (2001) The burden of musculoskeletal diseases in the general population of Spain: results from a national survey. Annals of the Rheumatic Diseases 60:1040-1045. https://doi.org/10.1136/ard.60.11.1040

34. Costedoat-Chalumeau N, Tamirou F, Piette JC (2018) Treatment adherence in systemic lupus erythematosus and rheumatoid arthritis: time to focus on this important issue: treatment adherence in SLE and RA. Rheumatology (Oxford, England). 857(9):1507-1509. doi: https://doi.org/10.1093/rheuma tology/kex337

35. Costedoat-Chalumeau N, Pouchot J, Guettrot-Imbert G (2013) Adherence to treatment in systemic lupus erythematosus patients. Best Pract Res Clin Rheumatol 27(3):329-340. https://doi.org/10.1016/.berh.2013.07.001

36. Anghel LA, Farcaş AM, Oprean RN (2018) Medication adherence and persistence in patients with autoimmune rheumatic diseases: a narrative review. Patient preference and adherence. 12:1151-1166. https://doi.org/1 $0.2147 /$ PPA.S165101

37. Monchablon C, Gondé H, Pouplin S, Varin R, Vittecoq O, Lequerré T (2020) Assessment of adherence to disease-modifying anti-rheumatic drugs in rheumatoid arthritis. Clinical rheumatology 39(1):207-216. https://doi.org/1 0.1007/s10067-019-04837-2

38. Gadallah MA, Boulos DN, Dewedar S, Gebrel A, Morisky DE (2015) Assessment of rheumatoid arthritis patients' adherence to treatment. The American journal of the medical sciences 349(2):151-156. https://doi.org/1 0.1097/MAJ.0000000000000376

39. Hromadkova L, Soukup T, VIcek J (2015) Quality of life and drug compliance: their interrelationship in rheumatic patients. Journal of evaluation in clinical practice 21(5):919-924. https://doi.org/10.1111/jep.12399

\section{Publisher's Note}

Springer Nature remains neutral with regard to jurisdictional claims in published maps and institutional affiliations.

\section{Submit your manuscript to a SpringerOpen ${ }^{\circ}$ journal and benefit from:}

- Convenient online submission

- Rigorous peer review

- Open access: articles freely available online

- High visibility within the field

- Retaining the copyright to your article

Submit your next manuscript at $\boldsymbol{\nabla}$ springeropen.com 